\title{
Influence of Continuing Education Program on Pharmacy Students' Knowledge about Generic Drugs in Saudi Arabia
}

\author{
Thamer A Almangour, Syed Wajid, Sultan Alghadeer, Abdul Aziz Alhossan, Salmeen D Babelghaith, Mohamed N Al-Arifi \\ Department of Clinical Pharmacy, College of Pharmacy, King Saud University, Riyadh, SAUDI ARABIA.
}

\begin{abstract}
Objectives: Currently, the use of generic medicines has increased globally. The purpose of this study was to evaluate the impact of education program (CEP) on future health care professionals' knowledge of generic medicines. Methods: A prospective, one-group, and pre- and post-test design was used to assess the effects of the educational program on future health care professionals' knowledge of generic medicines. The participants were final year pharmacy students a total of 24 Pharm.D students received the Continue education intervention. Findings: About $91 \%$ of them heard of generic medicines, with the most common source of information being the hospital $(16.7 \%)$, followed by teachers and lecturers (33.3\%). About $50 \%$ of them received generic medicine information from their course work. Most $91 \%$ of the respondents indicated that they had heard about generic and branded medicines. Pharm.D students' knowledge score significantly increased from 7.2 before the CEP program to 9.4 after. Conclusion: The
\end{abstract}

results of this study concluded that before the educational intervention, students had inadequate knowledge and misconceptions about generic medicine. CEP on generic medicines was effective in the improvement of the knowledge of future health care professionals.

Key words: Continuing Education, Future Health Care Professionals, Knowledge, Generic Medicine, Saudi Arabia.

Correspondence

Dr. Syed Wajid

Department of Clinical Pharmacy, College of Pharmacy King Saud University, Riyadh, SAUDI ARABIA.

Phone: +966-0503754169

Email:wali@ksu.edu.sa

DOI: 10.5530/jyp.2021.13.16

\section{INTRODUCTION}

Currently, the use of generic medicines has increased globally. Generic medicines are considered to be cheaper than branded ones and therefore save expenses on medicine costs. ${ }^{1}$ A generic medicine is a drug or medication that produces the same functions in the body as the branded medicine in terms of safety, strength, route of administration, quality, performance characteristics, and intended use. ${ }^{2}$ National regulatory bodies in Saudi Arabia, such as Saudi Food Drug Authority (SFDA), have defined generic drugs as drugs that are no longer protected by patents and are approved for marketing by companies without the need for clinical trials. ${ }^{3}$ In addition, generic medicines are bioequivalent to branded medicines.

Internationally, the expenditure on drugs and active pharmaceutical ingredients is considered to be significant factor that leads to rising health care costs in many countries including Saudi Arabia. According to the Gulf Cooperation Council, the generic drug market reached a value of nearly USD 1,783 million in 2017; moreover, currently, Saudi Arabia represents its largest market in the Middle East, accounting for more than half the total market share. ${ }^{4}$ However previous studies have reported that more than $82 \%$ of the drugs utilized in Saudi Arabian market were imported. ${ }^{5}$ However, many European countries like Austria, Denmark, Finland, and Germany have also introduced substitution procedures for promoting generic medicines with replacement for branded ones. ${ }^{6-8}$

The global industries of both insurance agencies and governments have suffered from rapidly rising pharmaceutical expenditures. Thus, recommending drugs by their generic names and encouraging pharmacists to dispense prescriptions with generic medicines minimize the health care utilization and expenditures. ${ }^{9,10}$ Continuing education Programs (CEPs) with the help educational training/practicum have been recommended as an essential tool for health care professionals including pharmacists, to improve patient outcomes with the greatest results established in clinical outcomes. ${ }^{11}$ Earlier reports have revealed that CEPs can positively affect health care professionals' knowledge, attitudes, and performance. ${ }^{12}$ Previous data on pharmacy students' knowledge about generic medicine have revealed deficits in knowledge. ${ }^{13}$ Several studies published in Saudi Arabia and some other countries found that pharmacists and health care providers have inadequate information and/or trust in the generic medicines. ${ }^{14}$ CEPs for the pharmacist are vital to educate them on and promote the widespread use of generic medicine, especially for future health care providers, as their knowledge on generic medicine can impact their future concerning prescriptions and generic substitution patterns. ${ }^{15}$ Such interventions have been recommended in Saudi Arabia and other countries. This study was conducted to evaluate the impact of a CEP on future health care professionals' knowledge of generic medicines at a pharmacy college in the central region of Saudi Arabia.

\section{MATERIALS AND METHODS}

A prospective, one-group, and pre- and post-test design was conducted to assess the effects of an educational program on knowledge of generic medicines among future health care professionals in King Saud University College of Pharmacy Riyadh Saudi Arabia. The participants were final year pharmacy students (Pharm.D) who studying their Pharm.D course, a total of 24 Pharm.D students recruited to participate in the study. This study was approved by voice dean for graduate research studies and research ethics Committee College of pharmacy, King Saud University, prior to start the study procedure; however, all the study tools used in this study were reviewed and approved by ethics committee with the following reference number (4/2014). Written informed consent 
was obtained from the study participants and given surety that the data used in this study would be confidential and students have the rights to withdraw from the study at any point during the data collection or intervention. The participants of the students in this study were volunteers.

A well-structured study instrument to collect the data for this study was developed from extensive literature review that conducted studies in this regard (Chua et al. 2010) ${ }^{16}$ The questions used in those studies were first collected, organized, modified and, then redesigned and validated by the senior researchers. Eight experts in the field were asked to comment independently on appropriateness of the questions to assess the validity of the questionnaire. After the validation and comments consideration, a pilot study was initially conducted among senior staff with the help of the researcher at the King Saud University male campus, after explaining the study details, based on the results, the questionnaire was used with some minor modifications. This questionnaire measured the pharmacy students' level of knowledge and perceptions of generic medicines. It was adapted from Chua et al. 2010. ${ }^{16}$ The first section of the questionnaire consisted of demographic details of the participants, including gender, age group, years of experience, and source of information; and the second part of the questionnaire included 12 items on knowledge of generic medicines (Appendix 1).

The intervention consisted of a collaborative lecture, information leaflets, and educational book. The description of the intervention is as follows.

A 60-min lecture was conducted for the participants, which was prepared by senior pharmacy academic staff with the help senior pharmacists. The lecture covered the safety standards of generic medicines and their pharmacokinetic properties along with process of approval of generic medicines in Saudi Arabia. The lecture utilized resources in the form of educational booklets providing information about generic and branded medicines and issues related to safety and efficacy of generic drugs. A list

\section{Appendix 1: Representing the total questionnaires in the study}

\section{Questionnaire}

A drug that is produced and distributed without patent protection may still have a patent on the formulation but not on the active ingredients

A drug that is the property of company that manufactures it through research and development and markets it under a patent. No other companies are allowed to produce it until the patent expires.

All products that are approved by the Saudi Food and Drug Authority (SFDA) of generic equivalents can be considered therapeutically equivalent to the branded product.

A generic medicine is bioequivalent to a branded medicine.

Branded medicines are safer than generic medicines because they have been tested through bioequivalence studies.

Generic medicines are in the same dosage form (e.g. tablet, capsule) as the branded medicine.

Medicines manufactured by multinational companies are more reliable than those by national firms.

Branded medicines should be preferred to generic medicine in lifethreatening conditions.

Cost of treatment will be less if generic medicines rather than branded medicines are used.

Generic medicines are of inferior quality to branded drugs and hence are less expensive.

Generic medicines produce more side effects than branded medicines.

Branded medicines are required to meet higher safety standards than generic medicines. of available drugs was prepared by drug information pharmacists from the drug poison information center according to therapeutic categories and was distributed to the participants for quick reference.

Manual data entry was carried out from each completed survey questionnaire received from participants. The data did not provide any personal information of the surveyed respondents like name or address. Unique identifier associated with the survey questionnaire will be used to identify individual responses and analyze the data.

\section{Statistical analysis}

The data were analyzed using SPSS Version 22 for Windows for analysis. Descriptive statistics including percentages and frequency distribution were calculated for each variable. The Wilcoxon signed rank test was used to compare the differences between pre- and post-intervention scores. The level of significance was set a priori at $p \leq 0.05$. This study and its design were reviewed and approved by the Institutional Review Board. All guidelines related to confidentiality of students' information were followed.

\section{RESULTS}

All final year Pharm.D students $(n=24)$ from King Saud University College of Pharmacy were invited to the lecture, and all of them attended it, with a $100 \%$ response rate. All respondents were male $(n=24)$, had experience of working in a hospital, and aged between 23 and 26 years; about $91 \%$ of them heard of generic medicines, with the most common source of information being the hospital (16.7\%), followed by teachers and lecturers (33.3\%) Figure 1. About 50\% of them received generic medicine information from their course work.

When asked about drug products approved by the SFDA, regarding whether generic equivalents can be considered to be therapeutically equivalent to the branded product, $87.5 \%$ participants at pre-intervention and $91 \%$ at post-intervention agreed. Nearly $58.3 \%$ of the respondents in pre-test believed that generics are inferior in quality, which is why they are cheap and have more side effects. However, this increased to $74.2 \%$ in the post-test.

Moreover, $37 \%$ of them in pre-test compared to $16 \%$ in post-test agreed that in life-threating situations, generic medicines should not be considered. Most were able to distinguish between generic and branded medicines based on patents and propriety issues; when asked about how safer the branded medicines were than the generic medicines, about $37.3 \%$ respondents in pre-test compared to $83.3 \%$ in the post-test

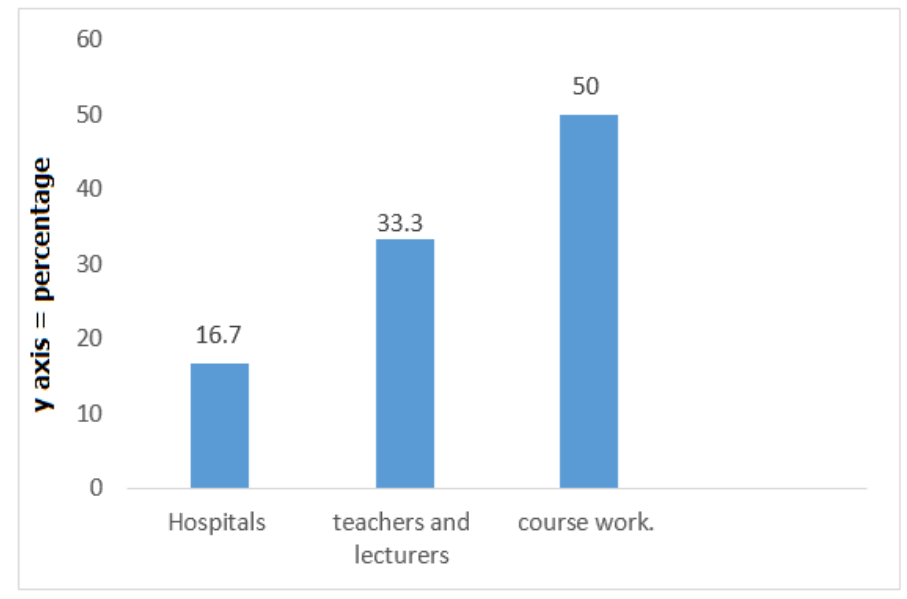

Figure 1: Sources of information on generic medicines 
perceived branded medicines to be safer due to extensive bioequivalence testing $(P=0.001)$.

In addition, when asked if the medicines manufactured by multinational companies are more reliable than those manufactured by national firms, 33.3\% answered correctly before the intervention, and after the intervention, the accurate response rate increased to $66.7 \%$, which was significant with $P$-value $<0.008$. Further details of comparison of correct response rate in generic medicine knowledge at pre- and post-intervention are shown in Table 1. However, Pharm.D students' knowledge score significantly increased from 7.2 before the CE program to 9.4 after it $(P=0.001)$ (Table 2).

\section{DISCUSSION}

Performance of health care professionals, especially physicians and pharmacists, is directly linked to effective health care outcomes ${ }^{17}$ as lifelong pursuit of knowledge and clinical skills are considered crucial. Continuing education has been shown to be effective by encouraging health care professionals to learn and improve through practice. ${ }^{17}$ In our study, the majority of the respondents (60\%) had knowledge about generic medicines before the educational lecture. After the educational intervention, the knowledge score increased to $78.9 \%$. The participants were Pharm.D students who had practice experience in a government hospital. However, many studies internationally used physicians from government and private sectors as the study subjects. ${ }^{18}$

Previous studies also indicated that practice of health care professionals is influenced by the type of working place; for instance, those with experience of working at government hospitals might have better knowledge of generic medicine than those with work experience in the private sector because generic drugs are largely used in public sectors. ${ }^{19-24}$

Table 1: Comparison of correct response rate in generic medicine knowledge at pre- and post-intervention.

\begin{tabular}{cccc}
\hline Items & $\begin{array}{c}\text { Pre-test Correct } \\
\text { Response (\%) }\end{array}$ & $\begin{array}{c}\text { Post-test Correct } \\
\text { Response (\%) }\end{array}$ & P-value \\
\hline Q1 & 62.5 & 62.5 & 1.0 \\
Q2 & 75 & 95.8 & 0.125 \\
Q3 & 87.5 & 91.7 & 0.125 \\
Q4 & 75.0 & 91.7 & 0.125 \\
Q5 & 37.3 & 83.3 & 0.001 \\
Q6 & 62.5 & 79.2 & 0.125 \\
Q7 & 33.3 & 66.7 & 0.008 \\
Q8 & 37.5 & 16.7 & 0.063 \\
Q9 & 79.2 & 100 & 0.063 \\
Q10 & 58.3 & 74.2 & 0.063 \\
Q11 & 75.0 & 91.7 & 0.125 \\
Q12 & 37.5 & 87.5 & 0.001 \\
\hline
\end{tabular}

McNemar test

Table 2: Knowledge score of respondents at pre- and postintervention.

\begin{tabular}{ccc} 
& Mean (median ) & $P$-value \\
\hline Pre-test score & $7.2(7)$ & 0.001 \\
Post-test score & $9.4(10)$ & \\
\hline
\end{tabular}

Wilcoxon Signed Ranks Test
Consequently, health care professionals can develop confidence through previous experience in generic medicine. Although studies demonstrating that involvement of healthcare professionals in CEP is vital to keep the ability to practice and ultimately to improve the quality of care and services delivered. However, participation in continuing education and training in skills and related activities has been confirmed to increase the knowledge and performance of health care workers. ${ }^{25}$

In this study, before the intervention, pharmacy students did not have adequate knowledge on the safety standards of generic medicine. However, the intervention improved this aspect. In Saudi Arabia, the SFDA is responsible for drug approval process. In fact, before the registration of new drugs, both generic and branded medicines are required to clear the rigorous registration process of ensuring safety, quality, and efficiency and that they meet the required international standards. For this purpose, manufacturers of both types of drugs comply with the requirements of good manufacturing practice. ${ }^{18,25}$

In this study, $83.3 \%$ respondents at post-test believed that branded medicines are safer due to extensive bioequivalence testing; however, our findings are better than those of another study on physicians that found that $66.7 \%$ were not aware of the bioequivalence standards for generic drug products. The possible reasons for this might be the small sample size, duration of interventions, and area of study. However, several factors and possible reasons would have contributed to such knowledge variations after interventions. Some studies indicated that it is easy to remember the branded medicines than generic medicine in the practice sites. ${ }^{6,23,26}$ Consequently, it is important to establish and encourage universities and pharmacy schools for the additional training programs that allow students to gain knowledge of pharmacy practice. This study in the education context found that majority of respondents believed that they can improve their knowledge through different strategies in education systems, including educational interventions. Furthermore, the long-term impact of the educational intervention is recommended. In addition, future studies with large sample size are warranted to investigate the impact of educational interventions. This study had several limitations. Firstly, the sample size of the study was very small and it is an intervention-based study. Secondly, the intervention was limited to short duration, and long-term effect of the educational intervention was not assessed. Thirdly, the study included only final year pharmacy students from a single institution.

\section{CONCLUSION}

The results of this study concluded that before the educational intervention, students had inadequate knowledge and misconceptions about generic medicine. CEP on generic medicines was effective in the improvement of the knowledge of future health care professionals. Additionally, we recommend that measures be taken to modify the curricula to ensure better understanding among future practitioners about the use of generic medicines.

\section{ACKNOWLEDGEMENT}

The authors of this study extended their appreciation to deanship of scientific research college of pharmacy King Saud University for supporting this study.

\section{REFERENCES}

1. Toklu HZ, Dülger GA, Hıdıroğlu S, Akici A, Yetim A, Gannemoğlu HM, et al. Knowledge and attitudes of the pharmacists, prescribers and patients towards generic drug use in Istanbul-Turkey. Pharm Pract. 2012;10(4):199-206.

2. US Food and Drug Administration (FDA). Approval of generic drugs. In: Generic drugs. Silver Spring. MD: FDA. 2008. http://www.fda.gov/ downloads/Drugs/ DevelopmentApprovalProcess/SmallBusinessAssistance/ ucm127615.pdf.

3. Saudi Food and Drug Authority. Regulatory frame work for drug approvals version 
5.0. 2014. https://www.sfda.gov.sa/ar/drug/resources/DocLib2/Regulatory_ Framework_for_Drug_Approvals_v_5\%200.pdf. IMARC-GCC Generic Drug Market: Industry trends, share, size, growth, opportunity and forecast 20182023. Retrieved from https://www.imarcgroup.com/gcc-generic-drug-market. Khan TM, Emeka P, Suleiman AK, Alnutafy FS, Aljadhey H. Pharmaceutical pricing policies and procedures in Saudi Arabia: A narrative review. Ther Innov Regul Sci. 2016;50(2):236-40.

4. McGettigan P, McManus J, O'shea B, Chan R, Feely J. Low rate of generic prescribing in the Republic of Ireland compared to England and Northern Ireland: prescribers' concerns. Irish Med J. 1997;90(4):146-7.

5. Garuoliene K, Godman B, Gulbinovič J, Wettermark B, Haycox A. European countries with small populations can obtain low prices for drugs: Lithuania as a case history. Expert Rev. Pharmacoeconomics Outcomes Res. 2011;11(3):3439.

6. Andersson K, Sonesson C, Petzold M, Carlsten A, Lönnroth K. What are the obstacles to generic substitution? An assessment of the behaviour of prescribers, patients and pharmacies during the first year of generic substitution in Sweden. Pharmacoepidemiol Drug Saf. 2005;14(5):341-8.

7. Hassali MA, Shafie AA, Jamshed S, Ibrahim MI, Awaisu A. Consumers' views on generic medicines: A review of the literature. Int J Pharm Pract. 2009;17(2):79-88.

8. Rada AG. Mandatory generic prescribing is expected to save Spain [euro] 2bn a year. BMJ. 2011;343.

9. Warholak TL, West D, Holdford DA. The educating pharmacy students and pharmacists to improve quality program: Tool for pharmacy practice. J Am Pharm Assoc. 2010;50(4):534-8.

10. Umble KE, Cervero RM. Impact studies in continuing education for health professionals: A critique of the research syntheses. Eval Health Prof. 1996;19(2):148-74.

11. Siam MK, Khan A, Khan TM. Medical and pharmacy students' knowledge and perceptions about generic medicines in Bangladesh. J Pharm Health Serv Res. 2013;4(1):57-61.

12. Wajid S, Al-Arifi MN, Al-Nomay HA, Al-Mousa YN, Babelghaith SD. Knowledge and perception of community pharmacists towards generic medicines in Saudi Arabia. Biomed Res. 2015;26(4).

13. Awaisu A, Kheir N, Ibrahim MI, El-Hajj M, Hazi H, Khudair N, et al. Knowledge, attitudes and practices of community pharmacists on generic medicines in Qatar. Int J Clin Pharm. 2014;36(2):394-404.

14. Chua GN, Hassali MA, Shafie AA, Awaisu A. A survey exploring knowledge and perceptions of general practitioners towards the use of generic medicines in the northern state of Malaysia. Health Policy. 2010;95(2-3):229-35.

15. Davis D, O'Brien MA, Freemantle N, Wolf FM, Mazmanian P, Taylor-Vaisey A. Impact of formal continuing medical education: Do conferences, workshops, rounds, and other traditional continuing education activities change physician behavior or health care outcomes?. JAMA. 1999;282(9):867-74.

16. Hassali MA, Wong ZY, Alrasheedy AA, Saleem F, Mohamad YAH, Aljadhey H Does educational intervention improve doctors' knowledge and perceptions of generic medicines and their generic prescribing rate? A study from Malaysia. SAGE Open Med. 2014;2:2050312114555722.

17. Bower AD, Burkett GL. Family physicians and generic drugs: A study of recognition, information sources, prescribing attitudes and practices. J Fam Pract. 1987;24(6):612-6.

18. DeRun EC, Mee-Kon NF. Patented and generic pharmaceutical drugs: Perception and prescription. Int J Bus Soc. 2006;7(2):55.

19. Ljungberg C, Lindblad ÅK, Tully MP. Hospital doctors' views of factors influencing their prescribing. J Eval Clin Pract. 2007;13(5):765-71.

20. Jamshed SQ, Hassali MA, Ibrahim MI, Babar ZU. Knowledge attitude and perception of dispensing doctors regarding generic medicines in Karachi, Pakistan: A qualitative study. J Pak Med Assoc. 2011;61(1):80-3.

21. Jamshed SQ, Ibrahim MI, Hassali MA, Masood I, Low BY, Shafie AA. Perception and attitude of general practitioners regarding generic medicines in Karachi, Pakistan: A questionnaire based study. Southern Med Rev. 2012;5(1):22.

22. Rodríguez-Calvillo JA, Lana A, Cueto A, Markham WA, López ML. Psychosocial factors associated with the prescription of generic drugs. Health Policy. $2011 ; 101(2): 178-84$.

23. Alrasheedy AA, Hassali MA, Stewart K, Kong DC, Aljadhey H, Ibrahim MI, et al. Patient knowledge, perceptions, and acceptance of generic medicines: A comprehensive review of the current literature. Patient Intelligence. 2014;6:1 29.

24. Hitchings AW, Baker EH, Khong TK. Making medicines evergreen. BMJ. 2012;29:345.

Article History: Submission Date : 28-12-2020; Revised Date : 21-01-2021; Acceptance Date : 12-02-2021

Cite this article: Almangour TA, Wajid S, Alghadeer S, Alhossan AA, Babelghaith SD, Al-Arifi MN. Influence of Continuing Education Program on Pharmacy Students' Knowledge about generic Drugs in Saudi Arabia. J Young Pharm. 2021;13(1):72-5. 